Running head: Experiences of mental health stigma

\title{
A qualitative study: experiences of stigma by people with mental health problems
}

Charlotte Huggett ${ }^{\mathrm{a}, \mathrm{c}}$, Michèle D. Birtel ${ }^{\mathrm{b}}$, Yvonne F Awenat ${ }^{\mathrm{a}, \mathrm{c}}$, Paul Fleming $^{\mathrm{a}}$, Sophie Wilkes $^{\mathrm{a}}$, Shirley Williams ${ }^{\mathrm{c}}$, and Gillian Haddock ${ }^{\mathrm{a}}$

Manuscript word count: 6000 (excluding abstract, references and table) Abstract word count: 192

\section{Corresponding Author}

Professor Gillian Haddock. University of Manchester, Division of Psychology and Mental Health, School of Health Sciences, Zochonis Building, Brunswick St, Manchester, M13 9PL. Fax: 0044161306 0406, telephone 0044161275 8485, e-mail:

gillian.haddock@manchester.ac.uk. 


\section{Contributors}

Authors MB, YA and GH designed the study. $\mathrm{CH}, \mathrm{MB}, \mathrm{PF}$, and SW analysed the data with input from the whole research team during project meetings. $\mathrm{CH}$ led preparation of the manuscript assisted by multiple critical revisions of the manuscript from all research team members. All authors have approved the final version of the manuscript.

\section{Acknowledgements}

The research reported in this article was funded by the University of Manchester Research Institute (Principal Investigator: Michèle Birtel), and was a collaboration between the University of Manchester, Stockport and District Mind and the University of Surrey. We would like to thank our volunteers Grace Bamber and Eleanor Smith, as well as Les Crabb (former manager at Stockport and District Mind) for their contribution to the research. 


\begin{abstract}
Objectives: Prior research has examined various components involved in the impact of public and internalised stigma on people with mental health problems. However, studies have not previously investigated the subjective experiences of mental health stigma by those affected in a non-statutory treatment seeking population.
\end{abstract}

Design: An in-depth qualitative study was conducted using thematic analysis to investigate the experiences of stigma in people with mental health problems.

Methods: Eligible participants were recruited through a local mental health charity in the North West of England. The topic of stigma was examined using two focus groups of thirteen people with experience of mental health problems and stigma.

Results: Two main themes and five subthemes were identified. Participants believed that (1) the 'hierarchy of labels' has a profound cyclical impact on several levels of society; people who experience mental health problems, their friends and family, and institutional stigma. Furthermore, participants suggested (2) ways in which they have developed psychological resilience towards mental health stigma.

Conclusions: It is essential to utilise the views and experiences gained in this study to aid understanding, and therefore, develop ways to reduce the negative impact of public and internal stigma. 


\section{Practitioner Points}

- People referred to their mental health diagnosis as a label and associated that label with stigmatising views.

- Promote awareness and develop improved strategies (e.g. training) to tackle the cyclical impact of the 'hierarchy of labels' on people with mental health problems, their friends and family, and institutional stigma.

- Ensure the implementation of clinical guidelines in providing peer support to help people to combat feeling stigmatised.

- Talking about mental health in psychological therapy or healthcare professional training helped to take control and develop psychological resilience. 
People with mental health problems not only have to cope with their primary condition, but may also experience the secondary impact of mental health stigma. Consequently, stigma itself has been described as a 'second illness' (Finzen, 1996).

Almost half (44\%) of people in England may experience a mental health problem in their lifetime (Health \& Social Care Information Centre, 2015) and approximately nine out of ten people with mental health problems report experience of stigma (Corker et al., 2016). Mental health stigma, therefore, continues to be a major issue that needs addressing. This research examines service user experiences and conceptualisations of stigma associated with mental health.

Goffman (1963) defines stigma as possession of a negative characteristic which discredits and segregates an individual from society. According to Social Identity Theory, this process involves the categorisation and stigmatisation of individuals resulting in an 'in-group' and an 'out-group' (Tajfel \& Turner, 1979). People experiencing mental health problems are perceived to belong to a minority 'out-group'.

Since Goffman's early work an extensive body of research has specifically explored stigma and mental health. Public and internalised stigma are often described in relation to mental health problems (Corrigan \& Watson, 2002). A large proportion of research identifies that individuals with mental health problems experience public stigma (stereotypes, prejudices, and discrimination) from the general population. A review of studies which examined mental health attitudes across Europe revealed that the public perceive people with mental health problems as unpredictable, violent and dangerous (Angermeyer \& Dietrich, 2006). Within the population labelled with mental health problems there are also gradations of stigma; higher levels of prejudice have been identified towards people with a diagnosis of schizophrenia (18-71\%) or substance misuse (65-71\%) than those with depression (14-33\%) or anxiety diagnoses (26\%; Angermeyer \& Dietrich, 2006). 
The biological approach to the aetiology of mental health problems assumes there is a physiological cause, which stems from abnormalities in brain structure and/or functioning (Andreason, 1985). Such explanations have been found to increase public acceptance and reduce blame and responsibility in people with mental health problems (Angermeyer, Holzinger, Carta, \& Schomerus, 2011). However, findings indicate that assertions of biogenetic aetiology of schizophrenia may increase public desire for social distance (Angermeyer et al., 2011) and lower social acceptance (Schomerus, Matschinger \& Angermeyer, 2014). Furthermore, the biological model may reduce empathy (Lebowitz \& Ahn, 2014) and perpetuate stigmatising views amongst healthcare professionals toward people with mental health problems (Schulze, 2007).

Beyond public reactions, those affected by mental health stigma have been identified as at risk of social isolation, inadequate healthcare, poor employment opportunities and inadequate housing (Corrigan \& Watson, 2002). People may cope with stigma in unique ways, resulting in, empowerment to change their future or damage to their perception of the future. The latter may enhance the impact of stigma and reduce their quality of life (Corrigan $\&$ Watson, 2002). Not only is this the case for people with mental health problems, but also their friends and family (Birtel et al., 2016).

Modified Labelling theory offers an explanation for the harmful effects stigma may have on people with mental health problems (Link et al, 1989). It suggests that society's attitudes toward people with mental health problems and connotations of receiving a diagnostic label are learnt through early socialisation. An additional, and detrimental, consequence of being labelled, may be that people with mental health problems accept and apply negative views, stereotypes and emotions to themselves i.e. 'internalise' stigma (Corrigan \& Watson, 2002). Increased severity of mental health problem and low levels of hope, self-esteem, empowerment and engagement with treatment are associated with 
internalised stigma (Livingston \& Boyd, 2010). Additionally, internalised stigma may be a help-seeking barrier for people with mental health problems due to feelings of shame and embarrassment (Clement et al., 2015).

According to the 'stigma-induced identity threat model' (Major \& O’Brien, 2005), individuals respond involuntarily (e.g. anxiety and vigilance) or voluntarily (e.g. avoidance and identifying with peers) to stigma. Recent studies have used randomised-control trials (RCTs) to assess the effectiveness of cognitive therapy (Morrison et al., 2013), and a mental health disclosure workshop (Corrigan et al., 2015). Both trials found that these interventions reduced the impact of internalised stigma.

Several qualitative studies have examined mental health stigma (Alvidrez, Snowden \& Kaiser, 2008; Easter, 2012; Mestdagh \& Hansen, 2014; Mittal et al., 2013). Qualitative research shows that education and disclosure of mental health problems reduced public stigma (Jensen \& Wadkins, 2007). Peer support and 'being, acting and looking 'normal'' facilitated the avoidance and anticipation of internal and public stigma (Whitley \& Campbell, 2014, p.7). These identify the negative emotional and behavioural reactions of those experiencing internal and public stigma. Burke, Wood, Zabel, Clark and Morrison (2016) found that individuals who experience psychosis felt shame, fear, anxiety, hopelessness and anger due to stigma. Participants described how negative past experiences contributed to social isolation and nondisclosure of mental health problems, which are risk factors for worsening mental health problems. Thus indicating a need to develop improved strategies to enable individuals with mental health problems to cope with stigma.

\section{The Current Research}

While research has examined the various components involved in the impact of public and internalised stigma, few studies have investigated the subjective experiences of mental health stigma by those affected, who were recruited through national charities (Bonnington \& 
Rose, 2014; Hayward, Wong, Bright \& Lam, 2002). To the authors' knowledge, this topic has not been previously examined using a sample recruited solely from non-statutory organisations, i.e. local charities. It is important to ensure a representative sample of those who would not necessarily be in contact with mainstream services and/or have limited contact with mental health professionals. Whilst some of this population may use both statutory and non-statutory services, they may well have different views and experiences of stigma than those solely recruited from statutory services. Service users may opt for non-statutory support as non-stigmatising support from peers can be facilitated and there may be less focus on mental health labels. This may be attractive due to previous experiences of mental health stigma. Therefore, the current study aimed to examine experiences and views of people with mental health problems, recruited through a local mental health charity, about mental health stigma.

\section{Method}

\section{Participants}

Participants were recruited using purposive sampling by age, gender and self-reported mental health diagnosis to ensure diversity in experiences (Ritchie, Lewis \& Elam, 2003). Participants were aged 18 or older, English-speaking, self-reported experience of stigma related to their mental health problem, and not currently experiencing an acute episode. Thirteen people with mental health problems were recruited into two focus groups. Participant demographic data are presented in Table 1.

\section{Insert Table 1}




\section{Procedure}

Ethical approval was granted by the university's research ethics committee. A university mental health service user group were consulted to advise on management of participant distress and study materials. The first author distributed a recruitment poster to local mental health charity groups and partner organisations inviting expressions of interest. Eligible participants provided informed consent and attended either Focus Group 1 (March, 2015) or 2 (April, 2015).

\section{Data collection}

Focus groups in a local community venue were selected to facilitate the naturalistic attainment of diverse views in a socially interactive manner that closely mimics 'real life' (Krueger \& Casey, 2009; Liamputtong, 2011). A flexible topic guide covered six areas: understanding of the term stigma, views and experiences of mental health stigma, public and internal stigma, effects of stigma, overcoming stigma, and priorities for stigma research. Focus groups lasted between 108.51 and 115.83 minutes, were audio recorded, and then transcribed verbatim by the first author.

\section{Data analysis}

Thematic Analysis was applied to the data using Braun and Clarke's (2006) 6-step approach. Co-authors listened to each audio recording and read the transcriptions to familiarise themselves and become immersed in the data. For each transcript, line-by-line coding was adopted producing 737 codes. Using pen and paper, codes were condensed and collapsed into 94 broad codes by the first, second, fourth and fifth authors. Broad codes were condensed into two main themes and five sub-themes. All co-authors provided input to review themes numerous times prior to agreeing the final themes. 


\section{Quality, rigour and impact}

Authors ensured "sensitivity to context" (Yardley, 2000, p.220) through provision of ethical participant care. For example, experienced researchers, who had extensive experience of working with the local mental health community, co-facilitated the focus groups. Psychology student volunteers assisted with data collection and analysis, including identifying and managing participant distress. One volunteer was trained to provide emotional support to participants. "Commitment and rigour" (p.221) were demonstrated by skilled facilitation of focus groups, accurate reporting of participant views, and attention to detail during analysis. Multiple coders were utilised to incorporate a range of interpretations of the data. All codes and themes were verified as data driven to ensure rigour. Transparency and coherence were adhered to by providing a detailed account of recruitment, data collection and data analysis. "Impact and importance" (p. 223) were exhibited by the wealth of data obtained from participants about their views on mental health stigma.

The project team comprised of individuals who vary in age and seniority, and have a diverse range of professional backgrounds, including, academic and clinical psychology, social work and nursing. This ensured broad and balanced analytical interpretations. Bespoke training was provided to those with participant contact, whereby reflexivity (Hellawell, 2006) was an important feature.

\section{Results}

The two main themes were: (1) Impact of 'hierarchy of labels' and (2) Developing psychological resilience, containing three (1) and two (2) subthemes respectively. A thematic map displaying themes and overlap of subthemes is provided in Figure 1.

\section{Insert Figure 1}




\section{(1) Impact of 'hierarchy of labels'}

This theme captured participants' perceptions of the impact and ripple effect of the 'hierarchy of labels' on (1.1) themselves as individuals with mental health problems, (1.2) their family and friends, (1.3) and institutional stigma.

\subsection{Self}

This subtheme highlighted the impact of stigma on people with mental health problems. The majority of participants discussed mental health problems in terms of the biomedical model, using phrases such as "I'm mentally ill” (FG1:P7). Participants identified their mental health diagnoses as labels and associated them with stigmatising views.

Internalised stigma was experienced by many participants and was perceived to be influenced by different diagnostic labels: "I think there's different levels of stigma attached to different diagnoses...if someone said that they had...psychosis or schizophrenia, might get slightly more stigma than someone with depression" (FG2:P5). Such views indicated perceptions of the existence of a 'hierarchy of stigma': "I think this idea of 'hierarchy of stigma' certainly affected me" (FG2:P4). Participants intimated that the 'hierarchy of stigma' resulted from public perceptions of the level of dangerousness of people with different diagnostic labels: "I think with depression, you're seen to pose less of a threat to other people" (FG2:P5). Physical health conditions were deemed to be at the bottom of the 'hierarchy of stigma': "If you got cancer, sympathy...Any kind of physical illness, you will get sympathy. But mental illness...you won’t get sympathy" (FG2:P6).

Societal stereotypes attached to participants' 'labels' were reported as directly related to internalised stigma. This notion links with the 'hierarchy of stigma'. Internalised stigma seemed to stem from participants' acceptance of their mental health diagnostic label and the negative connotations attached to such labels: “I think it's... self-stigma and once you've [got] 
a label, that's it, you are that label, you are that diagnosis. Especially if it's a serious disorder." (FG2:P2). The identification and perceived permanence of mental health diagnoses may have severe consequences for people with mental health problems, including suicidal feelings; "I was terrified of going to a Psychiatrist because I was terrified of the prospect of what I was experiencing would be life-long. So much so, I very nearly took my own life" (FG2:P2). Not only may these issues perpetuate experience of self-stigma, but also hinder mental health recovery.

People internalised stereotypes such as they were 'mad' and therefore 'not normal', with one participant explaining why they were once detained under mental health legislation: "I was an absolute nut-case" (FG1:P1) and another "can't be normal as a mum...because I've got this label, I can't do normal things now" (FG1: P3). Internalised stigma was described as one of the hardest impacts of stigma to overcome: "self-stigma...for me has been the obstacle" (FG2: P3).

Participants expressed a range of emotions in response to stigma. Some participants felt anxious about others finding out about their diagnosis due to fear of being stigmatised: "how down that made me...how paranoid I was, 'anyone's going to find out, oh my god"" (FG1:P2) and others voiced feelings of anger and blame towards themselves:

My anger's not out going towards people, my anger's to myself. So if a situation comes up and I'll think, is that my fault? I'll go away thinking it is my fault and that's when I start doing silly things. I self-harm.

(FG2:P1) 


\subsection{Expectations from family/friends}

Participants discussed the impact and invisible barrier of the 'hierarchy of stigma' when interacting with family and friends. Some described their relatives as reluctant to allow them to disclose their mental health problems. Family members themselves were reported to experience shame, self-blame and fear public reactions after their relative disclosed their mental health problem:

I think she was worried, partly because of reactions of the people towards me being open about it. But partly, a personal sense of shame because she has a son who she thought was plain sailing until he was like [age] and suddenly had a terrible breakdown.

(FG2:P4)

This sense of shame may partially explain why participants described their relatives as sceptical about their mental health problems; "I think the worst part is having a relative that does not believe that you have got mental health problems" (FG1:P4). This suggests the impact of the 'hierarchy of stigma' is two-fold as the impact on family members, also affects individuals. Furthermore, there are implied expectations of how people with mental health problems may behave and some people may not meet these expectations. Not only do family members hold these expectations, this also extends to friends, who were perceived to fear an association with people with mental health problems due to stereotypes: 
I used to have a lot of friends, and...once they found out I was schizophrenic, automatically assumed I was violent or whatever, for whatever reason. Who've just turn, kind of, not turned they're back on me, just moved on with their lives. (FG1:P1)

Evidently, and in line with the 'hierarchy of stigma', there were negative consequences for possessing a 'label,' which is perceived more negatively than other 'labels'. This affected participants due to loss of friendships and feelings of abandonment, which in turn could influence future social relationships.

\subsection{Institutional stigma}

Stigma appeared to affect organisations' policies, procedures and culture, which consequently impacted on people with mental health problems. Discussions identified stigma from both institutions themselves, such as hospitals, prisons, councils and the government, and individuals working within them. One person outlined the effect of the 'hierarchy of stigma' on their experience of disability benefit assessment centres;

Because of depression, you have to be assessed, don't you? And they are another [organisation] that do not take mental health issues into factor, they'll take everything else because they don't treat it with the seriousness that they should. (FG1:P4)

Evidently, participants felt the ignorance of staff in assessment centres perpetuated stigma, affected their mental health and facilitated the 'hierarchy of labels'. One participant 
perceived an existing hierarchy within accident and emergency departments and described how this was internalised;

Y' can't ring an ambulance, they're under stress anyway. They're only for emergencies. You've got to work out if your crisis is an emergency or not. So if you ring an ambulance and then you feel guilty because you've took an ambulance from somebody else.

(FG2:P1)

This suggests that not only do participants feel inferior to those who require ambulances for a physical health problem, they may also dismiss their own suicidal feelings and/or behaviours.

Another person illustrated how stigma influenced the culture of organisations and how that affected their experience in a psychiatric hospital:

All they're supposed to do is just watch you to see how you behave.... and when you're having a breakdown, it's just an absolute horrible place. I've been to prison and I'd much rather be in prison than be in one of those hospitals 'cos I just feel like they do not understand.

(FG1:P1)

Participants believed that stigma influenced their relationship with healthcare professionals, suggesting that healthcare professionals lacked understanding and distanced themselves. Participants agreed that healthcare professionals lacked understanding about participant's career prospects: "My GP said the exact same thing to me...I've got a diagnosis, 
but he said that I wouldn't expect to get a job in mental health if...you've had a mental illness." (FG1:P7). This demonstrates one of the long-term impacts that diagnoses had on the participant's life.

A fear of blame was attributed by participants to an increased use of labels by healthcare professionals: "I think, there's a tendency to over diagnose and I think there is also within that, a quickness to diagnose" (FG2:P2). This suggests that more people than necessary may be prone to experience the stigma associated to the label given.

The label, schizophrenia, was perceived to be higher in the hierarchy, than other diagnoses. Evidently, a greater fear of association was described as apparent due to the risk of criticism for the behaviour of healthcare professionals' patients:

They don't want to be the psychiatrist that let the one get away. You know, the one in a million schizophrenic, for example, that does go out and commit the murders. They don't want to be the psychiatrist that did that.

(FG2:P2)

To avoid blame, participants thought that healthcare professionals desired to remove the association: "if I can come up with some glib, quick thing that I think will be the remedy, do this, tick, that's off my back now, that's off my books" (FG2:P2). One way that participants thought professionals avoided blame was to prescribe medication: "This tablet will park the problem. Or alleviate the problem. It will get everyone else in the surroundings off the hook...people have their backs to cover." (FG2:P2). Participants further believed that distancing by healthcare professionals contributed to their lack of understanding. 


\section{(2) Developing Psychological Resilience}

This theme illustrated how people can cope with stigma by developing psychological resilience: through (2.1) taking back control and (2.2) having a support network.

\subsection{Taking back control}

Participants described how sharing experiences of stigma and mental health problems were helpful: "I addressed a room full of GPs about me and my problems and it's empowering" (FG2:P6). Participants also discussed how talking therapies or psychological interventions can be beneficial in aiding disclosure and coping with stigma: "I honestly think just talking through something can set your own mind straight and give you foresight to do what you need to do to get well" (FG1:P1). It was suggested that psychological therapy could particularly help people to develop resilience to combat perceptions of internalised stigma: "counselling helps dealing with how you perceive yourself and that's important because...everybody here's said...in the past they feel like people don't understand them and they feel stigmatised as I did" (FG1:P5).

Talking to a psychologist was perceived as beneficial in empowering participants to continue moving forwards despite the impact of stigma: "the changes I'd made from the first time she assessed me to the second time when she wrote another report [about] me, it's like, you have made changes, so you can change" (FG1:P3). Specific psychological therapies were mentioned as generally helpful, including "person-centred therapy" (FG2:P3) and "Mindfulness Based Cognitive Therapy (MBCT). Which dealt with all of those judging thoughts...I found that wonderful” (FG2:P2).

People described taking control when starting relationships by disclosing mental health problems: 
I always go with the approach that I'm going to have to mention it. ... as soon as I've kind of explained it and their up on [educated] mental health and they understand what it means, they're completely fine with it.

(FG2:P5)

This demonstrates that people are less likely to be a source of stigma once they gain direct personal experience and knowledge of mental health problems. Thus, participants thought disclosure was important to combat public and internalised stigma "Getting things off your chest on the one hand and then feeling that you're helping other people by showing you can live through things. Still be employed or employable and be honest about it" (FG2:P4).

This seemed to help some participants to feel proud of their mental health problems and empowered to disclose: "I am sick of hiding it, and I decided you know what? Yeah, I have got a mental health issue; I shout it off the roof now, because I don't care.” (FG1:P2). Disclosure appeared to be a result of people's personal strength and determination to not be defined as their 'label':

And once you've told them, they know exactly what you've got and you can relax then because you don't have to keep talking about it. I'm sick of talking about Depression to be quite honest. I want to get on with my life. But, it does affect me. I'm not ashamed of it. But, I deal with it. But, I don't want it to define me. I'm more than just an illness.

(FG1:P5)

On the other hand, taking control by disclosing mental health problems was described as difficult. People expressed the challenge of deciding who would understand and show 
acceptance after disclosure: “you'd know you can’t speak to them; you can't tell those people how you are. Because, you know that they wouldn't understand and it's just a gut feeling that you get." (FG1:P4). The threat that after disclosure the person might tell others prevented further disclosure: “I don't care if they don't like me, one person not liking me, I don't really care. But, if they start telling other people that I haven't even met..." (FG1:P5).

Although most people found that disclosure of their mental health problems helped them cope with stigma and accept their condition, when the group were asked how they deal with stigma one person responded "Don't tell anybody" (FG1:P4) implying that they cope with stigma through withdrawal or disclosure avoidance. This highlights the individuality in coping with stigma.

\subsection{Peer support}

People highlighted the importance of peer support networks and their ability to help develop psychological resilience to overcome stigma:

Everybody deals with it differently; some people can cope better because they've got a better support system around them [and] if someone's been through it themselves...some people don't have that kind of proper support network and they fall more often or crumble...then get stigmatised more for falling down. (FG1:P6)

Participants expressed that they felt more comfortable in the presence of others who had mental health problems “And you don't really speak to anyone who haven't got mental health problems." (FG1:P1). Participants then explained why their contact is limited: "They've gone through what you're going through" (FG1:P4) and "you know that people are 
all in a similar kind of boat as you and you can feel like you can just relax. But, you're not alone" (FG1:P5). Peer support was suggested as preferential to participants as they did not have to worry about being stigmatised. Peer support networks also provided a space for people to talk about their mental health problems so they could focus on other areas of their lives; "if you can find different groups that can take that part of your life, you can put it in that pigeon hole. That frees you up to have a bit of a life yourself" (FG2:P2).

Although participants described peer support as helpful in terms of combatting stigma, limiting contact in this way also appeared to lead to isolation:

It leaves you to live a solitary lifestyle. I have support, I have a support worker and I have one good friend. I don't really speak to anybody else outside of that. It's very solitary and it's just the way it's become.

$(\mathrm{FG} 1: \mathrm{P} 1)$

\section{Discussion}

\section{Overall}

Findings of the current study provide a meaningful contribution to the limited research, which explores service user experiences of mental health stigma. Examination of the data indicates that the 'hierarchy of labels' has a profound cyclical impact on several levels; people who experience mental health problems, their friends and family, and institutional stigma. Additionally, people with mental health problems develop psychological resilience to overcome stigma through taking control of their diagnostic label and developing support networks.

Whitley and Campbell (2014) reported that people in supported living facilities rarely spoke about experiences of public stigma within their focus groups. Discussions revolved 
around fear of perceived public stigma, which was echoed by participants in the current study. However, participants in this study additionally spoke of many instances in which they were stigmatised. Experiences may differ as those living in supported living facilities may have a wider range of support needs and therefore more prone to stigmatisation, than individuals associated with a local mental health charity.

\section{Impact of 'hierarchy of labels'}

\section{Self}

Many studies have compared stigmatising attitudes to different diagnoses and have described how members of the public attach higher levels of stigma to diagnoses associated with dangerousness and unpredictability (Angermeyer \& Dietrich, 2006). This is reflected in the current findings, whereby participants described this as a 'hierarchy of stigma' and within the hierarchy, individuals created their own 'in-groups' and 'out-groups'. This further suggests the impact of differing levels of stigmatisation dependent on diagnostic labels. Thus, providing support for and demonstrating Modified Labelling theory (Link et al, 1989). Furthermore, participant's language in relation to labels suggests they have internalised society's view of the 'sick role' (Parsons, 1951). People who adopt this notion do so unknowingly and become exempt from continuing with traditional social activities. They are expected to try to get well and seek help (Parsons, 1951). However, due to the stigma attached to mental health problems and the longevity of labels, the 'sick role' potentially led participants to blame themselves for their mental health problem.

Internalised stigma results from public stigma and is widely recognised in the literature as an issue which needs addressing due to its' detrimental effects on people with mental health problems (Bos, Kanner, Muris, Janssen \& Mayer, 2009; Clement et al., 2015; Corrigan et al., 2010; Corrigan et al., 2015; Livingston \& Boyd, 2010). Several participants in the current study were seemingly unaware that their statements demonstrated internal stigma. 
However, some participants were aware of internal stigma and its' negative effect: this is consistent with the literature.

A recent qualitative study reported that participants had a variety of emotional responses to internalised stigma (Burke et al., 2016). Participants in the current study shared similar emotional responses such as fear, anger, worry, shame, and depression. However, and additionally, participants in the current study experienced self-blame, suicidality, and worthlessness in response to internalised stigma. These responses were not mentioned by participants in Burke et al.'s (2016) study. Differences may be due to participants in the current study being recruited from non-statutory services. Furthermore, some participants in the current study employed social avoidance and non-disclosure to cope with internalised stigma, findings that are supported by the literature (Burke et al., 2016; Yanos, Roe, Markus \& Lysaker, 2008; Vass et al., 2015). These means of coping have been reported to lead to loss of relationships (Burke et al., 2016) and reduced help-seeking (Vogel, Wade \& Haake, 2006), which are described in the current study.

\section{Expectations from family/friends}

People with mental health problems reported that their family and friends were dismissive, over-protective, and disbelieving of their mental health problems. They commented that family and friends distanced themselves and were reluctant to disclose their friend or family member's mental health problem (Hamilton et al., 2014). The current study supports and takes these results further. Participants attempted to explain the reasons for these behaviours and attributed them to fear, self-blame and shame.

Interestingly, participants in the current study did not refer to their friends or family members as 'carers', whereas, in other research friends, family and partners, identify themselves as 'carers' for people with mental health problems. A parent-carer identified the need for training in the awareness and impact of expressed emotion as they may be unaware 
of the potential harmful effects of their verbal and non-verbal communications (Birtel et al., 2016). The need for training and awareness reflected in these findings provide an alternative explanation for the perceived fear, self-blame and shame experienced by participants' relatives in the current study. Thus demonstrating the profound and cyclical impact that stigma can have on family, friends and people with mental health problems themselves.

\section{Institutional stigma}

Evidently, societal beliefs about mental health problems are adopted and facilitated by organisations and healthcare professionals, which could be explained by Modified Labelling theory (Link et al, 1989). Institutional stigma can often lead to internalised stigma and loss of opportunities (Corrigan, Markowitz \& Watson, 2004), which is demonstrated in the present findings. Disability benefit assessments, ignorance and stigma were raised, in the current study, as important issues to address. A longitudinal ecological study in England found an association between an increase in reassessments for disability benefits and an increase in suicides, antidepressant prescriptions, and mental health prevalence (Barr et al., 2015). The current study provides support and a possible explanation for these findings. Participants felt that assessors lacked understanding and were ignorant of mental health problems, which perpetuated mental health stigma.

A wealth of research reports stigmatising attitudes (Newton-Howes, Weaver \& Tyrer, 2008; Rao et al., 2009; Schulze, 2007) and behaviours (Burke et al., 2016; Thornicroft, Rose \& Kassam, 2007) by healthcare professionals towards people with mental health problems. Furthermore, UK-based studies (Newton-Howes, Weaver \& Tyrer, 2008; Rao et al., 2009) found that healthcare professionals have differing attitudes towards different diagnoses (e.g. personality disorder, depression, schizophrenia and substance misuse). This is comparable to the current study as it suggests that healthcare professionals are affected by and perpetuate the 'hierarchy of stigma'. Furthermore, mental health stigma may influence practice and, 
consequently, may be detrimental to service users. This could be why participants felt that healthcare professionals lacked understanding. The current study provides insight from the service user perspective on the impact of stigma on healthcare professionals, however, future qualitative studies could explore this matter further with healthcare professionals themselves. Participants attributed over-diagnosing, prescribing medication and early discharging of service users to fear of blame for the actions of people with mental health problems.

Interestingly, in interactions with healthcare professionals about career prospects, some participants defied Parsons' notion of the sick role (1951). Their desire for a career within the mental health field was met with a perceived lack of understanding and stigma from healthcare professionals. This suggests that healthcare professionals may have perceived the participant as still in the 'sick role', which could have been due to the power imbalance and expectations within their relationship.

\section{Developing psychological resilience}

\section{Taking back control}

Some participants in the current study suggested that talking therapies may be useful in combatting the impact of public and internal stigma. MBCT was described by one participant as beneficial in dealing with judgmental thoughts. Although MBCT does not appear to have been tested in relation to felt and internalised stigma reduction, cognitive therapy was found to be effective in reducing internalised stigma in people experiencing psychosis (Morrison et al., 2013). This suggests that talking therapies could be investigated further as a stigma reduction technique.

Within the literature, disclosure of mental health problems is widely discussed. Goffman (1963) discussed the notion of impression management by stigmatised individuals and how selecting information to share regarding their discrediting characteristic would facilitate control over their public-image. Some people with mental health problems feel they 
cannot disclose, or disclose 'altered' information about their mental health problem (Dinos, Stevens, Serfaty, Weich \& Kind, 2004), which Goffman (1963) defined as 'passing'. This reflects one individual's experience reported in the current study. On the other hand, choosing to disclose a mental health problem has been associated with lower self-stigma and higher quality of life than non-disclosure (Bos et al., 2009; Corrigan et al., 2010). These findings are echoed in the current study. Some participants disclosed their mental health problem in order to not be defined by their label. Therefore, this adds further validity to claims that mental health disclosure may have a positive impact.

Disclosure of a mental health problem may be important in help-seeking. Concerns over disclosure due to public or internal stigma have been linked to reduced help-seeking (Clement et al., 2015). The positive effects of disclosure have been the basis for developing a technique in America to support individuals in the 'coming out' process; 'coming out proud' (Corrigan et al., 2015). An initial RCT found that the intervention significantly reduced agreement and application of stereotypes and harm caused by self-stigma (Corrigan et al., 2015). Although some participants in the current study reported positive experiences in disclosure, they also found it difficult and some opted not to disclose their mental health problem. This suggests it may be beneficial to support people in the disclosure process and further research could investigate the above technique in a UK population.

\section{Peer support}

Peer support is broadly discussed in the literature within the context of a recovery model and is recommended by government guidelines (NICE, 2011;2015). Findings from the current study suggest that mental health peer support is a means of combatting felt stigma. Studies have consistently found through self-report questionnaires (Watson, Corrigan, Larson, \& Sells, 2007) and focus groups (Whitley \& Campbell, 2014) that peer support was protective against public stigma and helped reduce internal stigma. Interestingly, participants in the 
current study did not mention peer support in relation to their recovery. Participants valued the idea of interacting with people who have similar experiences, suggesting that participants actively sought out support from their 'in-group' for non-stigmatising interactions. However, this could in turn facilitate their 'out-group' status and, therefore, facilitate public stigma. This notion supports Social Identity theory (Tajfel \& Turner, 1979). On the other hand, another qualitative study reported that people may find peer relationships difficult and would like to form relationships not based on shared mental health characteristics (Angell, 2003). Even though some participants in the current study were aware that their social contact may be limited to people with mental health problems, they were positive about peer relationships. Participants may be more positive towards peer support as they were recruited from a mental health charity. Charities are experienced in providing peer support groups and so may have normalised this type of support for participants, making them more comfortable and open to the idea.

\section{Limitations}

A significant limitation was that around eight participants dominated focus group discussions. Whilst the facilitators attempted to manage group dynamics by identifying and engaging with quiet participants, several participants contributed less to group discussions than others. If individual interviews were conducted, the researchers may have been able to gain more feedback from quiet participants. On the other hand, due to group dynamics, some participants potentially gave more information due to memories triggered by other participant feedback.

The majority of participants in the sample were white British. This reflects the population associated with the local mental health charity used for recruitment. The authors would have welcomed more diversity in the sample, enabling insight into mental health stigma in people from different ethnic and cultural backgrounds. People from ethnic 
minorities report experiences of mental health stigma within their own communities due to religious or cultural beliefs, and are less likely to seek and receive support for mental health problems (Knifton, 2012; Nadeem et al., 2007). Further studies could consult service user groups to tailor recruitment strategies to ethnic minority groups.

Nonetheless, the results highlight that the 'hierarchy of labels' is prevalent on several levels; individuals with mental health problems, their friends and family, and institutional stigma. In summary, the findings may be an important contribution to understanding the subjective views of people with mental health problems about the impact of, and developing psychological resilience toward, mental health stigma.

\section{References}

Alvidrez, J., Snowden, L.R., \& Kaiser, D.M. (2008). The experience of stigma among Black mental health consumers. Journal of Health Care Poor Underserved, 19(3), 874-93. doi:10.1353/hpu.0.0058

Andreasen, N.C. (1985). The broken brain: The biological revolution in psychiatry. New York: Harper \& Row

Angell, B. (2003). Contexts of social relationship development among assertive community treatment clients. Mental Health Services Research, 5(1), 13 - 25. doi:10.1023/A:1021703424197

Angermeyer, M.C., \& Dietrich, S. (2006). Public beliefs about and attitudes towards people with mental illness: a review of population studies. Acta Psychiatrica Scandinavica, 113(3), 163-179. doi:10.1111/j.1600-0447.2005.00699.x

Angermeyer, M.C., Holzinger, A., Carta, M.G., \& Schomerus, G. (2011). Biogenetic 
explanations and public acceptance of mental illness: systematic review of population studies. The British Journal of Psychiatry, 199, 367-372.

doi:10.1192/bjp.bp.110.085563

Barr, B., Taylor-Robinson, D., Stuckler, D., Loopstra, R., Reeves, A., \& Whitehead, M. (2015). 'First, do no harm': are disability assessments associated with adverse trends in mental health? A longitudinal ecological study. Journal of Epidemiology \& Community Health, 70, 339-345. doi:10.1136/jech-2015-206209

Birtel, M.D., Haddock, G., Bamber, G., Huggett, C.L., Williams, S., \& Awenat, Y. (2016). Impact of Stigma by Association in Mental Health Care: Carers' Challenges in Health Care Interactions and the Need for support. Unpublished manuscript.

Braun, V., \& Clarke, V. (2006). Using thematic analysis in psychology. Qualitative Research in Psychology, 3, 77-101. doi: 10.1191/1478088706qp063oa

Bonnington, O., \& Rose, D. (2014). Exploring stigmatization among people diagnosed with either bipolar disorder or borderline personality disorder: A critical realist analysis. Social Science and Medicine, 123, 7-17.

doi:10.1016/j.socscimed.2014.10.048

Bos, A.E.R., Kanner, D., Muris, P., Janssen, B., \& Mayer, B. (2009). Mental Illness Stigma and Disclosure: Consequences of Coming out of the Closet. Issues in Mental Health Nursing, 30(8), 509-513. doi:10.1080/01612840802601382

Burke, E., Wood, L., Zabel, E., Clark, A., \& Morrison, A. (2016). Experiences of stigma in Psychosis: A qualitative analysis of service users' perspectives. Psychosis, 8(2), 130-142. doi:10.1080/17522439.2015.1115541

Clement, S., Schauman, O., Hraham, T., Maggioni, F., Evans-Lacko, S., Bezborodovs, N., ...Thornicroft, G. (2015). What is the impact of mental 
health-related stigma on help-seeking? A systematic review of quantitative and qualitative studies. Psychological Medicine, 45, 11-27.

doi:10.1017/S0033291714000129

Corker, E., Hamilton, S., Robinson, E., Cotney, J., Pinfold, V., Rose, D., ... Henderson, C. (2016). Viewpoint survey of mental health service users' experiences of discrimination in England 2008-2014. Acta Psychiatrica Scandinavica, 134 (446), 613. doi:10.1111/acps. 12610

Corrigan, P.W., \& Watson, A.C. (2002). Understanding the impact of stigma on people with mental illness. World Psychiatry, 1(1), 16-20.

Corrigan, P.W., Markowitz, F.E., Watson, A.C. (2004). Structural Levels of Mental Illness Stigma and Discrimination. Schizophrenia Bulletin, 30(3), 481-491.

Corrigan, P.W., Morris, S., Larson, J., Rafacz, J., Wassel, A., Michaels, P., ... Rush, N. (2010). Self-stigma and coming out about one's mental illness. Journal of Community Psychology, 38(3), 259-275. doi:10.1002/jcop.20363

Corrigan, P.W., Larson, J.E., Michaels, P.J., Buchholz, B.A., Del Rossi, R., Fontecchio, M.J., ...Rüsch, N. (2015). Diminishing the self-stigma of mental illness by coming out proud. Psychiatry Research, 229, 148-154. doi:10.1016/j.psychres.2015.07.053

Dinos, S., Stevens, S., Serfaty, M., Weich, S., \& Kind, M. (2004). Stigma: the feelings and experiences of 46 people with mental illness. The British Journal of Psychiatry, 184(2), 176-181. doi:10.1192/bjp.184.2.176

Easter, M.M. (2012). "not all my fault": genetics, stigma, and personal responsibility for women with eating disorders. Social Science and Medicine, 75(8), 1408-16. doi:10.1016/j.socscimed.2012.05.042

Finzen, A. (1996). Der Verwaltungsrat ist schizophren. Die Krankheit und das 
Stigma. Bonn: Psychiatrie-Verlag

Foreign \& Commonwealth Office. (2015). Mental health and travelling abroad.

London: Foreign and Commonwealth Office

Goffman, E. (1963). Stigma. London: Penguin

Hamilton, S., Lewis-Holmes, E., Pinfold, V., Henderson, C., Rose, D., \& Thornicroft, G. (2014). Discrimination against people with a mental health diagnosis: qualitative analysis of reported experiences. Journal of Mental Heath, 23(2), 88-93. doi:10.3109/09638237.2014.880408

Hayward, P., Wong, G., Bright, J.A., \& Lam, D. (2002). Stigma and self-esteem in manic depression: an exploratory study. Journal of Affective Disorders, 69(1-3), 6167. doi:10.1016/S0165-0327(00)00380-3

Health \& Social Care Information Centre. (2015, December 16). Health Survey for England, 2014: Chapter 2: Mental health problems. Retrieved from http://content.digital.nhs.uk/catalogue/PUB19295

Hellawell, D. (2006) 'Inside-out': analysis of the insider-outsider concept as a heuristic device to develop reflexivity in students doing qualitative research. Teaching in Higher Education, 11(4) 483-494. doi:10.1080/13562510600874292

Jensen, L.W., \& Wadkins, T.A. (2007). Mental health success stories: Finding paths to recovery. Issues in Mental Health Nursing, 28(4), 325-340. doi:10.1080/01612840701244086

Knifton, L. (2012). Understanding and addressing the stigma of mental illness with ethnic minority communities. Health Sociology Review, 21(3), 287-298. doi:10.5172/hesr.2012.21.3.287

Krueger, R.A., \& Casey, M.A. (2009) Focus Groups: A Practical Guide for Applied Research. London: Sage 
Lebowitz, M.S., \& Ahn, W. (2014). Effects of biological explanations for mental disorders on clinicians' empathy. PNAS, 111(50), 17786-17790. doi:10.1073/pnas.1414058111

Liamputtong, P. (2011). Focus Group Methodology: Principle and Practice. London: Sage.

Link, B.G., \& Phelan, J.C. (2001). Conceptualizing stigma. Sociology, 27, 365-385. doi:10.1080/01612840802601382

Link, B. G., Struening, E., Cullen, F. T., Shrout, P. E., \& Dohrenwend, B. P. (1989). A MODIFIED LABELING THEORY APPROACH TO MENTAL-DISORDERS - AN EMPIRICAL-ASSESSMENT. American Sociological Review, 54(3), 400-423. doi:10.2307/2095613

Livingston, J.D., \& Boyd, J.E. (2010). Correlates and consequences of internalized stigma for people living with mental illness: A systematic review and meta-analysis. Social Science \& Medicine, 71(12), 2150-2161. doi:10.1016/j.socscimed.2010.09.030

Major, B., \& O’Brien, L.T. (2005). The Social Psychology of Stigma. Annual Review of Psychology, 56, 393-421. doi:10.1146/annurev.psych.56.091103.070137

Mestdagh, A., \& Hansen, B. (2014). Stigma in patients with schizophrenia receiving community mental health care: a review of qualitative studies. Social Psychiatry and Psychiatric Epidemiology, 49(1), 79-87. doi:10.1007/s00127-013-0729-4

Mittal, D., Drummond, K.L., Blevins, D., Curran, G., Corrigan, P., \& Sullivan, G. (2013). Stigma associated with PTSD: perceptions of treatment seeking combat veterans. Psychiatric Rehabilitation Journal, 36(2) 86-92. doi:10.1037/h0094976

Morrison, A.P., Birchwood, M., Pyle, M., Flach, C., Steward, S.L.K., Byrne, R., ... 
French, P. (2013). Impact of cognitive therapy on internalized stigma in people with at-risk mental states. The British Journal of Psychiatry, 203, 140-145.

doi:10.1016/j.psychres.2016.04.024

Nadeem, E., Lange, J.M., Edge, D., Fongwa, M., Belin, T., \& Miranda, J. (2007).

Does Stigma Keep Poor Young Immigrant and U.S.-Born Black and Latina Women from Seeking Mental Health Care? Psychiatric Services, 58(12), 1547-1554. doi:10.1176/ps.2007.58.12.1547

Newton-Howes, G., Weaver, T., \& Tyrer, P. (2008). Attitudes of staff towards patients with personality disorder in community mental health teams. Australian \& New Zealand Journal of Psychiatry, 42(7), 572-577.

doi:10.1080/00048670802119739

NICE. (2011). Common mental health problems: identification and pathways to care. Retrieved from https://www.nice.org.uk/guidance/cg123/chapter/1-guidance

NICE. (2015). Psychosis and schizophrenia in adults: prevention and management. Retrieved from https://www.nice.org.uk/guidance/cg178/ifp/chapter/Peer-support-and-selfmanagement

Parsons, T. (1951). ILLNESS AND THE ROLE OF THE PHYSICIAN: A SOCIOLOGICAL PERSPECTIVE. American Journal of Orthopsychiatry, 21(3), 452-460. doi:10.111/j.1939-0025.1951.tb00003.x

Rao, H., Mahadevappa, H., Pillay, P., Sessay, M., Abraham, A., \& Luty, J. (2009). A study of stigmatized attitudes towards people with mental health problems among health professionals. Journal of Psychiatric and Mental Health Nursing, 16, 279-284. doi:10.1111/j.1365-2850.2008.01369.x 
Ritchie, J., Lewis, J., \& Elam, G. (2003). Designing and selecting samples. In Ritchie, J., \& Lewis, J. (eds.) Qualitative Research Practice. Sage: London

Schomerus, G., Matschinger, H., \& Angermeyer, M.C. (2014). Causal beliefs of the public and social acceptance of persons with mental illness: a comparative analysis of schizophrenia, depression and alcohol dependence. Psychological Medicine, 44, 303314. doi:10.1017/S003329171300072X

Schulze, B. (2007) Stigma and mental health professionals: A review of the evidence on an intricate relationship. International Review of Psychiatry, 19(2), 137-155. doi:10.1080/09540260701278929

Schulze, B., \& Angermeyer, M.C. (2003). Subjective experiences of stigma. A focus group study of schizophrenic patients, their relatives and mental health professionals. Social Science \& Medicine, 56, 299-312. doi:10.1016/S0277-9536(02)00028-X

Tajfel, H., \& Turner, J. (1979).An integrative theory of intergroup conflict. In W. Austin \& S. Worchel (eds.) The Social Psychology of Intergroup Relations (33-48). CA: Brooks/Cole.

Thornicroft, G., Rose, D., \& Kassam, A. (2007). Discrimination in health care against people with mental illness. International Review of Psychiatry, 19(2), 113-122. doi:10.1080/09540260701278937

Vass, V., Morrison, A.P., Law, H., Dudley, J., Taylor, P., Bennett, K.M., \& Bentall, R.P. (2015). How stigma impacts on people with psychosis: The mediating effect of self-esteem and hopelessness on subjective recovery and psychotic experiences. Psychiatry Research, 230(2), 487-495. doi:10.1016/j.psychres.2015.09.042

Vogel, D.L., Wade, N.G., \& Haake, S. (2006). Measuring the Self-Stigma Associated with Seeking Psychological Help. Journal of Counseling Psychology, 53(3), 325-337. doi:10.1037/0022-0167.53.3.325 
Watson, A.C., Corrigan, P., Larson, J.E., \& Sells, M. (2007). Self-Stigma in People With Mental Illness. Schizophrenia Bulletin, 33, 1312-1318. doi:10.1093/schbul/sb1076

Whitley, R., \& Campbell, R.D. (2014). Stigma, agency and recovery amongst people with severe mental illness. Social Science \& Medicine, 107, 1-8. doi:10.1016/j.socscimed.2014.02.010

Yanos, P., Roe, D., Markus, K. \& Lysaker, P. (2008). Pathways between internalized stigma and outcomes related to recovery in schizophrenia spectrum disorders. Psychiatric Services, 59(12), 1437-1442. doi:10.1176/appi.ps.59.12.1437

Yardley, L. (2000). Dilemmas in qualitative health research. Psychology and Health, 15, 215-228. doi:10.1080/08870440008400302 


\section{Tables}

\section{Table 1}

Participant demographic information

\begin{tabular}{|c|c|c|c|c|c|c|}
\hline$P p$ ID & Gender & Age & Ethnic Group & $\begin{array}{c}\text { Mental Health } \\
\text { Problem } \\
\text { Y/N }\end{array}$ & $\begin{array}{l}\text { Identify } \\
\text { self as a } \\
\text { Carer } \\
\mathrm{Y} / \mathrm{N}\end{array}$ & $\begin{array}{l}\text { Self-reported mental health } \\
\text { problem }\end{array}$ \\
\hline${ }^{\mathrm{a}} \mathrm{FG1:1}$ & $\mathrm{M}$ & 35 & White British & $\bar{Y}$ & $\bar{N}$ & $\begin{array}{c}\text { Depression and Paranoid } \\
\text { Schizophrenia }\end{array}$ \\
\hline FG1:2 & $\mathrm{F}$ & 30 & White British & $Y$ & $Y$ & $\begin{array}{c}\text { Depression, Anxiety, Addict, } \\
\text { Alcoholic, Dual Diagnosis }\end{array}$ \\
\hline FG1:3 & $\mathrm{F}$ & 28 & White British & $Y$ & $\mathrm{~N}$ & $\begin{array}{c}\text { Depression, Anxiety, } \\
\text { Borderline Personality } \\
\text { Disorder }\end{array}$ \\
\hline FG1:4 & $\mathrm{F}$ & 69 & White British & $Y$ & $\mathrm{~N}$ & No answer \\
\hline FG1:5 & $M$ & 49 & $\begin{array}{c}\text { Mixed - English, } \\
\text { Chinese }\end{array}$ & $Y$ & $\mathrm{~N}$ & Depression \\
\hline FG1:6 & $M$ & 30 & White British & $Y$ & $\mathrm{~N}$ & $\begin{array}{l}\text { Clinical Depression and } \\
\text { Social Anxiety Disorder }\end{array}$ \\
\hline FG1:7 & $\mathrm{M}$ & 21 & White British & $\mathrm{N}$ & $\mathrm{N}$ & Psychosis \\
\hline FG2:1 & $\mathrm{F}$ & 52 & White British & $Y$ & $\mathrm{~N}$ & $\begin{array}{l}\text { Depression, Anxiety, self- } \\
\text { harm, suicidal thoughts }\end{array}$ \\
\hline FG2:2 & $M$ & 41 & White British & $\mathrm{N}$ & $\mathrm{N}$ & No answer \\
\hline FG2:3 & $\mathrm{F}$ & 39 & $\begin{array}{c}\text { Mixed - Latin } \\
\text { American }\end{array}$ & $\mathrm{Y}$ & $\mathrm{N}$ & Depression \\
\hline FG2:4 & $M$ & 54 & White British & $Y$ & $\mathrm{~N}$ & $\begin{array}{c}\text { Past experience - } \\
\text { Depression, Anxiety, } \\
\text { aggression and alcohol } \\
\text { addiction }\end{array}$ \\
\hline FG2:5 & $\mathrm{F}$ & 26 & White British & $\mathrm{N}$ & $\mathrm{N}$ & One episode of psychosis \\
\hline FG2:6 & $M$ & 67 & White British & Y & $\mathrm{N}$ & Clinical Depression \\
\hline
\end{tabular}


${ }^{\mathrm{a}}$ Focus Group 1

\section{Figures}

Figure 1. Illustration of overlap between sub-themes in each theme

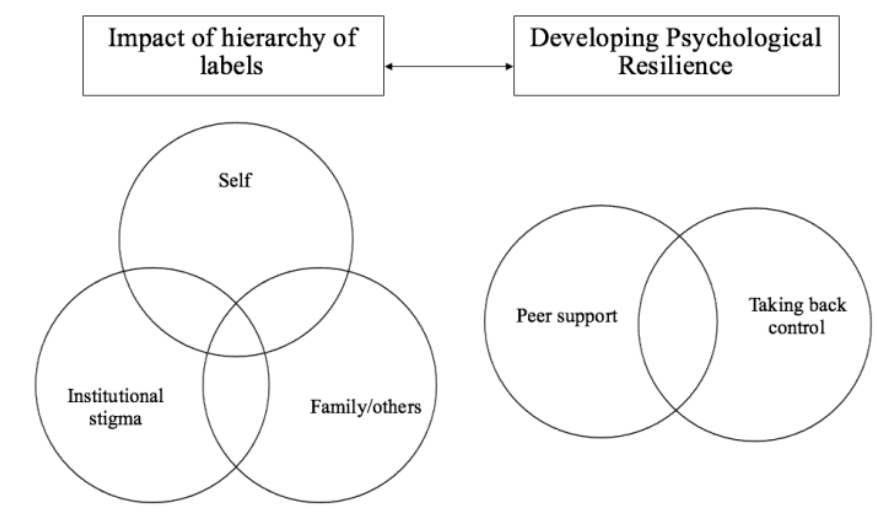




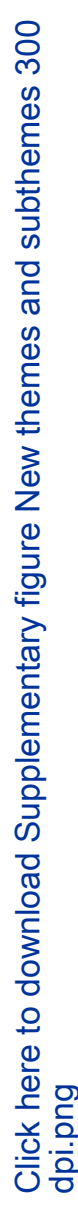

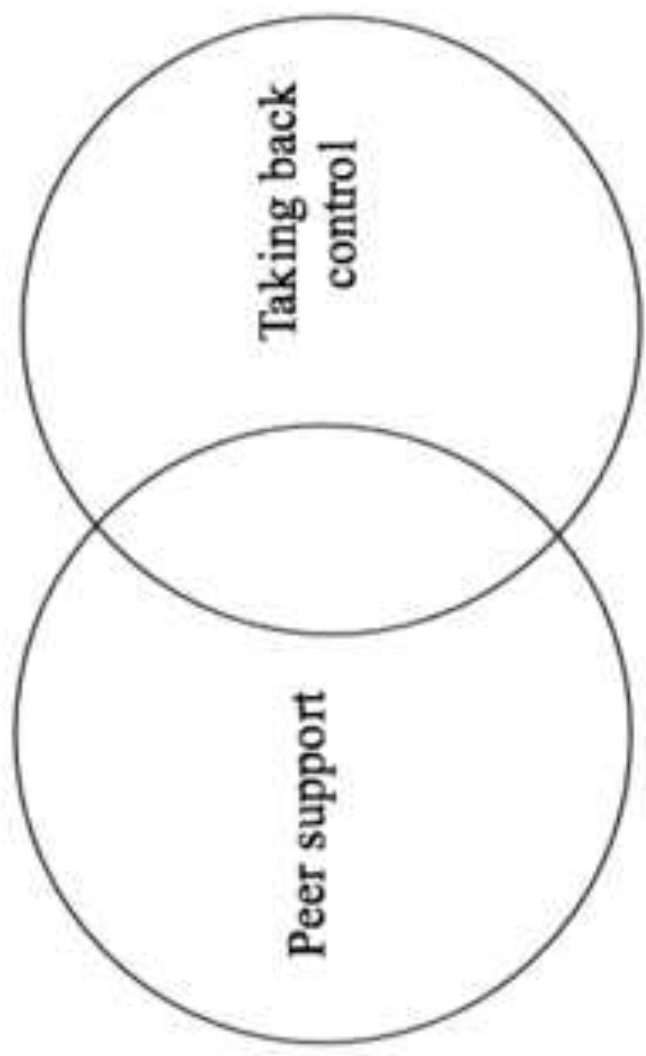

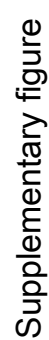
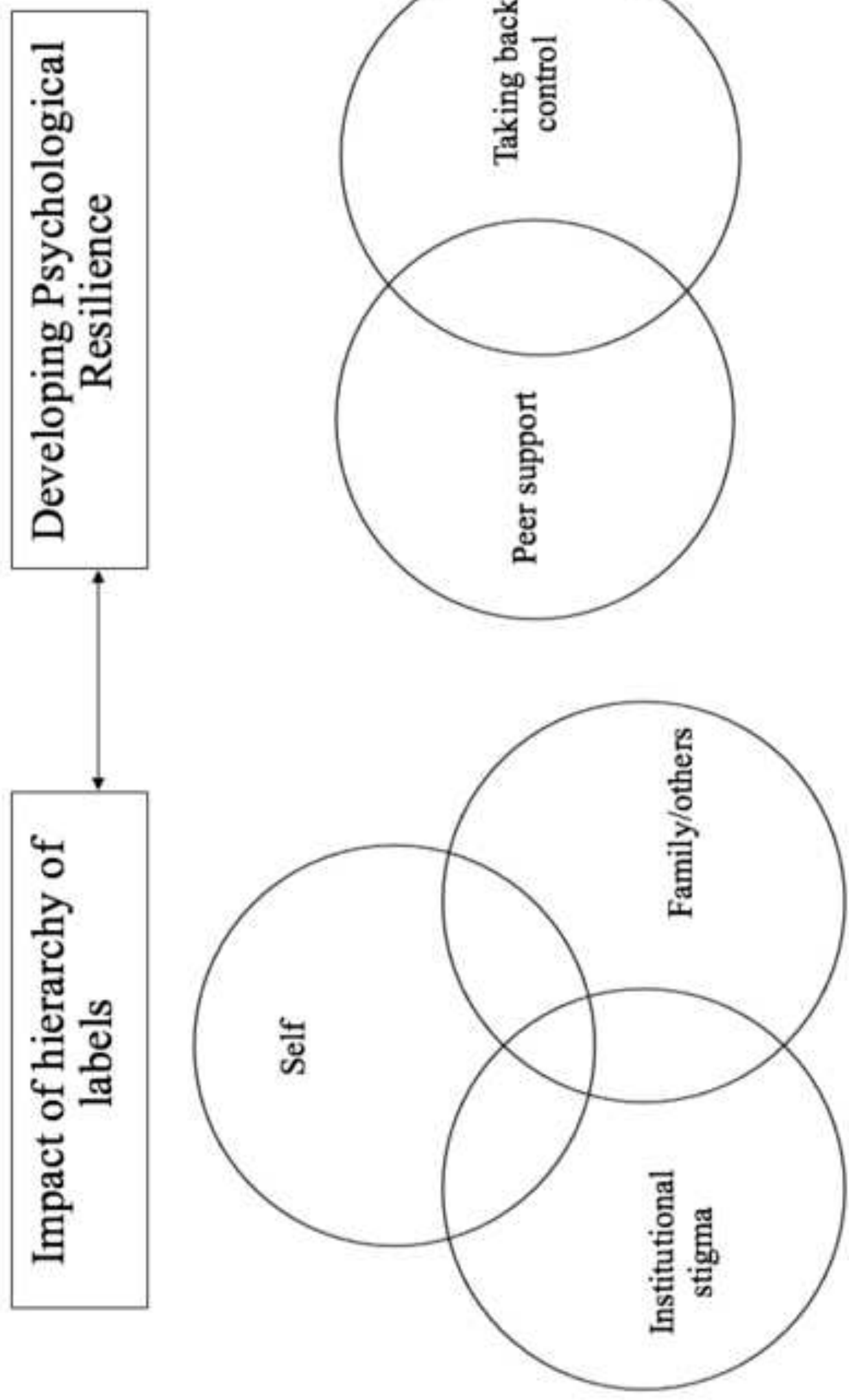